By HAROLD D. LASSWELL

\title{
The Science of Communication and the Function of Libraries
}

$\mathrm{T}_{\mathrm{l}}$ HE FUTURE Historian of the intellectual life of our times will undoubtedly choose as a dominant theme the trend toward integrating the social sciences with one another and with policy. The developing science of communication is a case in point.

That there is a new scientific discipline in the making is by this time clearly demonstrable. There are institutes and committees at Chicago, Columbia, Denver, Harvard, Ohio State, Princeton, Stanford, and Yale; and the list is not complete. The Rockefeller Foundation has supported research programs in this field, chiefly at the initiative of the Humanities Division (David H. Stevens, John Marshall). Since the war the tempo has increased and closer working relations have been cemented between science and policy, notably in connection with radio. With the advent of broadcasting, it is possible for any belligerent to listen to the voice of the enemy and to interpret the meaning of what is said for every branch of policy, whether strategy, diplomacy, economics, or communication. Since the beginning of World War II every major power has set up monitoring services to record enemy broadcasts and to examine their total significance.

\section{Converging Intellectual Development}

Even a cursory glance at the tributaries that feed the new interest in communication discloses that something new is taking place under the academic sun. We are accus- tomed to think that the social and humanistic sciences are becoming more specialized and more remote from the mother matrix of philosophy. For a century new branches of learning have struck out for themselves. In recent years, however, evidences of parallel and converging development are visible in every special discipline.

The evolution of political science and public law is representative of the new trend. During the age of separatism scholarly reputations were made by studying institutions and doctrines. The literature described the growth of parliament or the history of political speculation since the Greeks. In recent years interest has shifted from the "forms" to the "facts," from the "structure" to "what makes it tick." And this has led to research on one part of the process of communication, namely, public opinion. A precursor of this tendency is the volume by A. V. Dicey, the distinguished specialist on English public law, called Lectures on the Relation Between Law and Public Opinion in England During the Nineteenth Century. James Bryce, Graham Wallas, A. Lawrence Lowell, and Charles E. Merriam continued this line of growth.

In the science of economics somewhat similar trends can be discerned. Among English, American, and Austrian economists the dominant tendency was to perfect the theoretical structure of the subject and to sacrifice "concrete detail" for a limited number of postulates. This emphasis was 
by no means unanimous, and the reaction against it produced such subtle studies of economic life as the brilliant essays of Thorstein Veblen. Concerned with other elements in behavior than the rational calculation of gain, Veblen gave full recognition to the role of fashion and other nonrational determiners of conduct.

The part played by "informal means of social control," expressed in the process of communication, was fully stressed by sociologists. American scholars such as Sumner, Ross, Cooley, and Park have had much to say about "fashion," "public opinion," "crowd states," "gossip," and other factors of this kind.

Specialists on language have always tended to go beyond the study of grammar to inquire into the role of language in the whole of life. In recent decades one linguist and ethnologist, Edward Sapir, has given masterly treatment to selected aspects of communication and has inspired a number of emulators. Closely akin to linguistics in breadth is comparative literature. Among contemporary scholars, I. A. Richards has been very successful in analyzing the whole process of discourse.

Since it is impossible for any school of psychology to overlook the communicative process, the subject has been enriched by practically every group of specialists. Freud generalized some of his own findings from the clinic to society, and the leaders of behavioristic and Gestalt schools have addressed themselves to this topic. The emerging synthesis has gained from the mother matrix, philosophy. Building on the work of George H. Mead, Charles S. Peirce, and others, Charles W. Morris has provided a provisional theory of communication in Foundation of the Theory of Signs.

Side by side with converging developments within the central sciences of society has gone the professional expansion of edu- cation, public speaking, drama, creative writing, advertising, public relations, journalism, and librarianship.

\section{The Structure of the Science}

The give-and-take of many specialists has evolved a common point of view toward the nature of the communication process. The key question about the process is: Who says what, to whom, with what effect? The study of "who" is control analysis; the study of "says what" is content analysis; the study of "effect" is effect analysis.

A few examples will quickly show what is meant. Leo C. Rosten described the social background and the personal characteristics of newspapermen and of moviemakers in The Washington Correspondents and Hollywood. All such studies of owners, regulators, and contributors of each channel of communication are part of control analysis. The problem is to find out what they intend to communicate, how they intend to do it, and what factors influence intention.

German Radio Propaganda by Ernst Kris, Hans Speier, and associates, is an instance of content analysis. The book is a detailed quantitative and interpretative study of German home broadcasts after 1939. Other media and other situations have been examined by other scholars for the purpose of giving an objective picture of "what is said."

In the field of effect analysis may be mentioned a joint product of Paul Lazarsfeld, Douglas Waples, Bernard R. Berelson, and associates. During the presidential campaign of 1940 a single county was intensively described for the purpose of explaining the final vote in terms of the influence of campaign propaganda and of previous political behavior (predisposition).

For many scientific purposes it is con- 
venient to enlarge the threefold division of the field of communication. Media analysis may be devoted to the physical network of communication. Content analysis may be subdivided into the study of "purport" and "style." A separate division may be made of "intention" in order to focus upon conceptions of strategy and tactics.

\section{Bibliography of Communication}

One way to obtain a quick view of the science of communication is to look at the problem of classifying titles in the field. The present writer was chairman of a committee appointed several years ago by the Social Science Research Council to inquire into the state of research on "public opinion and pressure groups." The committee decided to pool resources and edit an annotated bibliography as a guide to the literature. The framework devised at the time has since been used to classify titles and to cover the expanding conception of research on communication. ${ }^{1}$

Part I includes titles that purport to be about general theories of propaganda, methods closely related to propaganda, or, finally, general theories of the symbolic process. Examples are: Sergei Chakhotin, The Rape of the Masses; The Psychology of Totalitarian Political Propaganda; Farago and Gittler, eds., German Psychological Warfare: A Survey and Bibliography; John William Albig, Public Opinion.

Part II brings together the titles that emphasize the maker of the communication, whether government, voluntary association, or private individual. Example: James L. McCamy, Government Publicity; Its Practice in Federal Administration.

\footnotetext{
${ }^{1}$ Lasswell, Harold D., Casey, R. D., and Smith, B. L. Propaganda and Promotional Activities; An Annotated Bibliography. Minneapolis, University of Minnesota Press, 1935. 450p. A new volume forthcoming from the Princeton University Press in 1945 is "Propaganda, Public Opinion and Communication; An Annotated Bibliography" by B. L. Smith, Harold D. Lasswell, and R. D. Casey.
}

The third part includes every title that puts the stress on the goal of the communication, like Merle Eugene Curti's American Peace Crusade, 1815-1860. Part IV is the place for titles that describe the symbols used in making communications. Books and articles that describe the key symbols, slogans, and doctrines of a group or of a whole society or historical period, go in IV. One such title is Wilhelm Bauer's History of Public Opinion (in German), the only survey of the entire history of opinion.

Part V describes the channels; Part VI, the measurement of effects; and Part VII, the function and control of communication. Hence Part V embraces a book like Louis Round Wilson's Geography of Reading; Part VI, Cantril, Gaudet, and Hertzog's Invasion from Mars: A Study in the Psychology of Panic; With the Complete Script of the Famous Orson Welles Broadcast; Part VII includes Free Speech in the United States by Zechariah Chafee.

A title list assigns books somewhat differently than does a scientific scheme. Hence, the bibliography does not classify books in terms that are exactly comparable with the subdivisions of the science of communication mentioned above. However, certain rough equivalencies do exist. Control analysis is directly touched in Parts II and VII of the bibliography and in the sections of Part $\mathrm{V}$ that refer to owners, regulators, and contributors. Content analysis is especially involved from II through V. Effect analysis is highly concentrated in VI. If media analysis is thought of separately, many appropriate titles are found in V. If intention analysis is also given special prominence, pertinent literature is in Part I.

Perhaps the foregoing sketch has been enough to provide an idea of the present scope of the growing science of communication. If so, we are in a position to consider the connection between the science and the task of modern librarianship. 


\section{The Role of the Librarian}

Since I am a political scientist, I make the following remarks with all due reserve. I take it for granted that modern librarians are not satisfied to be the guardians of the community wastebasket, but that they play a dynamic role in deciding what to conserve and what to neglect. Moreover, I take it for granted that one of the major functions of the library in civilized society is to prepare the sources for future historical and scientific understanding of the ever-expanding present. This implies that in a profound sense the progress of social intelligence depends upon the energy and vision of librarians, for intelligence in society depends upon insight and insight must be nourished upon research into the social inheritance and into the processes of social growth. And research is conditioned and limited by the sources; the anticipation of useful sources is the peculiar challenge of librarianship.

The scientific study of communication provides at least one intellectual tool of great potential usefulness to the librarian who faces the burden of choosing among contemporary sources. This tool is a concept, the concept of the focus of attention. Why this concept is important appears when we reflect on the nature of human response and remember that what people do is an outcome of two sets of determinative factors, one environmental, the other predispositional. When people buy, vote, or fight, they are responding to changes in their environment on the basis of the predispositions with which they entered it. Through any given day, month, season, year, decade, or generation, the environment of social groups is changing; and the acts of response by members of the group become part of the predisposition for the next contact with the environment. The observing and recording of social history is the process of describing for any period of time the interrelations of response and environment.
When we examine the social process from this point of view, we are made aware of another point: the part of the environment that most directly affects response is what comes to the attention of the potential responder. If we want to explain individual or group response, it is necessary to give special emphasis to facts about the focus of attention. To some extent this is a matter of describing group exposure to media of communication and calls for the record of broadcasts, magazines, newspapers, lectures, sermons, speeches, demonstrations, posters, theatrical performances, film shows. But it goes beyond media to the world of immediate experience, to the persons and objects of home, neighborhood, and workplace. If we are to create a scientifically useful record of the changing experience of representative groups in America or in any society during a selected period, we must somehow keep a significant record of what comes to the attention of the group.

\section{What Librarian Should Do}

The problem can be tackled in a systematic way by the librarian. The first question is to decide what communities are to be covered by the library in question, and with what degree of intensity. To some degree every repository in the world tries to provide some sources of information about the world as a whole. But in practice this quickly fades into highlighting certain nations, continents, regions, cities, localities, and certain economic, political, social, racial, religious, linguistic, sex, age, skill, and other groups. That such coverage is incomplete, and will always be incomplete, is obvious. The problem gets interesting when one faces up to the question of how to make the incomplete as rational as possible. This calls for the application of selective principles, of which the first has already been stated: select communities (global, continental, regional, local) for "very intensive," "less in- 
tensive," and only "extensive" coverage.

After these choices have been made the next problem is to choose the social values whose distribution is to be sampled in the chosen communities. Representative social values are power, income, respect. (A value is an object of desire; the social structure is the grouping of people according to their share in the production and distribution of values during selected periods.) Specialists on social structure are usually sociologists, and the librarian can use them, together with economists who study population shifts, as consultants.

When the value list has been chosen, the next question is what population characteristics to choose in studying the degree of participation in the values. In the American nation, for instance, it is common knowledge that people with black skins do not have the same relative share of power, income, or respect as people with white skins. Hence, this is a significant criterion to use. Sharing also varies according to age, sex, skill (occupation, profession), linguistic accomplishment, religious attitude; and there are other differentiating indexes as well. Facts about the social structure are not only availáble from government reports and university research but from the commercial research of many private firms, and the library can wisely enlarge its staff of consultants to tap these vats of material.

\section{Organizations in the Community}

The next question concerns the network of organizations found in the communities whose social structure is known. It is possible to choose from among the many organized bodies those bearing a characteristic relationship to social structure. Some associations, such as certain women's clubs, may be affiliated with upper income and respect groups; others, like some foreign language benevolent orders, may be heavily concentrated among low respect groups. Still others, like some political associations, draw members and officers from nearly all strata of society. (Insight into community structure in our civilization can be gained from such authors as W. Lloyd Warner and P. S. Lunt describing Yankee City, a series published by the Yale University Press.)

When the foregoing decisions have been provisionally made, it is possible to proceed rationally to the choice of sources that reveal the focus of attention on mass media. The library itself circulates to individuals occupying a determinate position in the local structure of society, and proper library records are exceedingly valuable (and improvable) sources of knowledge about the changing focus of attention. ${ }^{2}$ Publishers in the larger cities know to what extent their newspapers circulate in high, middle, or low income areas. Information is also available about the popularity of radio stations and programs in different income groups. $^{3}$ In a less satisfactory state is information about audiences at downtown and neighborhood motion picture houses. Inferences can be made regarding poster and sign audiences from traffic surveys or from occasional researches.

It is perhaps needless to call attention to the fact that it is necessary to keep in mind the distinction between channels originating locally and those originating outside the selected area. From various public and private sources estimates can be made of the circulation of outside newspapers, magazines, and radio broadcasts.

When the mass media have, been chosen it is useful to return to the consideration of the public and private organizations and to decide which sources about each are to

2 See, notably, Douglas Waples' People and Print: Social Aspects of Reading in the Depression. (University of Chicago Studies in Library Science) Chicago,

sity of Chicago Studies in Library Science) Chicago,
University of Chicago Press, I938. 228p.
3 For general orientation, see Paul Lazarsfeld's Radio and the Printed Page. New York City, Duell, Sloan \& Pearce, 1940. 354p. 
be covered. This is a matter of gauging the nature and frequency of organized activities that come to the attention of members and nonmembers. Meetings of many types can be recorded, including the agenda and minutes of business sessions of the membership at large and of officials. (In many cases the material must be held in confidence by the repository for an agreed upon period of years.)

Since committee meetings involve intense interaction between response and attention, they are of great social importance. It is possible to describe different groups in the committee (conference, legislature, or assembly) in terms of what it does and of what comes to its attention that others do.

\section{Direct Experience}

The next step is to bring the attention focused on mass media and on organized participations into proper perspective in relation to direct experience. What are the typical patterns of attention that characterize various groups? Common sense and research unite in affirming that there are great differences in the daily, seasonal, and long-term attention patterns of many elements of any population. Some housewives limit themselves to the household and pay little attention to mass media or organized meetings. To some extent these differences vary according to income level, but they are related to many other factors, such as agrarian or urban environment and level of education.

Very little systematic information is at hand about the activity calendar, including the focus of attention of representative groups. Several methods have been applied to the problem of acquiring such data, however. Volunteers have kept diaries or participant observers have noted the behavior of persons with whom they are associated. ${ }^{4}$ Under these circumstances it may be feasible for librarians themselves to take the leadership in the gathering of data. I do not intend by this suggestion to imply that this is their responsibility solely ; indeed, the responsibility is quite as much that of the historian, political scientist, sociologist, social psychologist, or other specialized and well-equipped person. My only point is that among the many opportunities for leadership in the expanding of social intelligence, the librarian can at least consider this one. By his initiative he may create a team of competent persons in his community and embark upon a continuing program of basic importance. In Great Britain the mass observation movement has succeeded in enlisting a great deal of voluntary aid from citizens throughout the length and breadth of the country. In America social scientific development has tended to be the province of highly trained professionals who have made little effort to interest the community as a whole in the enterprise. And both science and the community have lost something. Our studies have a high technical polish in many cases, but they do not contribute as fully as they might to social insight into the processes and problems of our society. Under the impetus of the war, psychologists and social scientists have taken the initiative in "rumor clinics" or in some other form of continuous observation and report on trends in communication. The librarian who reaches out for contact with interested persons may discover a powerful ally in his local university, college, normal school, or high school. Also, the level of commercial research has been rising in recent years, and many able persons are now engaged in it.

\section{Librarian's Consultants}

If the librarian organizes a team of consultants, he may be able to launch many

- For instance. see Pitirim A. Sorokin and Clarence Q. Berger's Time-Budgets of Human Behavior. (Harvard Sociological Studies, v. 2.) Cambridge, Harvard University Press, 1939. 204p. 
routines that contribute material of great usefulness to his resources. Consider, for instance, the possibilities of a regular photographic reconnaissance of selected points in the locality or region. At periodic intervals the major traffic centers can be photographed in order to bring out the posters and signs, thus adding to our documentation of public attention. Local camera clubs are often eager for guidance and would gladly participate in a community history project. Members of such clubs and of local history societies can be prevailed upon to keep diaries or to make reliable participant-observer notes.

By proper planning the librarian and his associates can introduce the serial principle into types of records where it has not previously applied. The simplest way to introduce it is to look at the same place at regular intervals. This is the advantage of photographing the announcements visible at traffic centers at regular seasons of the year. Ordinarily records of this kind are left, if at all, in haphazard fashion, and their historical and scientific usefulness is much reduced.

If the program here projected is carried out, it is obvious that libraries must be willing to handle far more diversified types of material than has been conventional in the past. A library of recordings, for instance, is necessary if radio broadcasts are to be properly covered. Scripts are of less value than what actually goes out over the microphone (although libraries can wisely arrange with local stations to turn over scripts, from which selections can be made; such scripts are usually destroyed after a protection period running from six months to two years). Arrangements can be made to obtain recordings of locally originating programs of various types at all seasons of the year. A valuable source is the "log" of a radio station, since all programs are a matter of record. At regular intervals the $\log$ should be photographed. Besides recordings, the library needs to make provisions for films. By cooperating with local newspapers it is often possible to cover significant local events with proper sound and motion picture equipment.

Another type of material of great potential value is research data, especially original data sheets and other work papers used in local community studies. Local polls may be conducted after the pattern made well known by George Gallup and Elmo Roper (Fortune). Social psychologists also use intensive interviews and other means of data gathering. ${ }^{5}$

Librarians and library consultants will do well to give special thought to the task of sampling the highly specialized media of mass communication. Newspapers are recipients of thousands of words of material per day over the press association news ticker, by mail, by phone, by interview. Only a fraction of the "input" is eventually used. It is important to have the raw material available for selection at each step of the editing process. Hence, the "editor's wastebasket" ought to be emptied at stated periods as part of the social history of communication.

\section{Conclusion}

In what has been said up to this point, no mention has been made of how the science of communication bears upon the communication problem of the library itself. I have deliberately sacrificed this part of the subject in order to focus upon the long-term contribution that wise librarianship can make to social intelligence. Emphasis has been put upon the scientific importance of describing the changing structure of community attention, but I cannot refrain from

\footnotetext{
5 An excellent statement of the tools available for research on communication is in Douglas Waples, Bernard R. Berelson, and Franklyn R. Bradshaw's What Reading Does to People. (University of Chicago Studies in Library Science) Chicago, University of Chicago Press, 1940. 222p.
} 
saying that the focus of attention is of more than scientific importance. By examining what comes to the notice of people we are enabled to gain insight into their inner lives. One way to know the mountaineer, the plainsman, or the shore dweller; to permeate into the lives of city people, villagers, and countrymen; to get behind the masks of residents of Moscow, Chungking, or Chi- cago-in short, one, way to understand the thoughts and feelings of man-is to become acquainted with what he has seen, heard, touched, and read. ${ }^{6}$

6 These and many other points are developed in Print. Radio, and Film in a Democracy: Ten Papers on the Administration of Mass Communications in the Public Interest, Read before the Sixth Annual InstiPublic Interest, Read before the Sixth Annual Insti-
tute of the Graduate Library School, the University of Chicago, August 4-9, I94I. Waples, Douglas, ed. Chicago, University of Chicago Press, 1942. I97p.

Comment by Glen Burch

\section{Communication and the Community}

Dr. Lasswell's suggestion that librarians take the initiative in promoting and carrying on a piece of social research at the community level-and specifically in the realm of the science of communication-is an extremely provocative one. It is refreshing indeed to find a scientist who thinks well enough of the profession of librarianship to believe that its members are capable of taking leadership in performing a piece of research in his own field. Public librarians (and I think it is clear that Dr. Lasswell's remarks are addressed primarily to them) are not popularly supposed to have any great capacities for research.

Dr. Lasswell apparently is not only willing to have librarians take the leadership in this research project; he envisages them carrying it out in cooperation with a group of amateur social scientists! This is going to be pretty strong stuff for many of his fellow scientists, but I believe Dr. Lasswell is on firm ground. For it is perfectly true that "in America social scientific development has tended to be the province of highly trained professionals who have made little effort to interest the community as a whole in the enterprise," and it is probably high time that something was done about it. As a practical way in which to begin to get community participation in social research, Dr. Lasswell's proposal may be open to question. But in placing emphasis on the greater lay experience in and responsibility for this kind of activity, he is beyond doubt pointing up one of the profound needs of our time. As a matter of fact, of course, the need for greater community participa- tion in this kind of research is beginning to be met in some towns and cities through the medium of the social survey. Hundreds, possibly thousands, of communities have conducted social surveys of one kind or another in the process of making plans for that postwar world. Some have been pretty badly done. But some have been remarkably good. And in all instances quite a number of lay people have become acquainted with at least one tool of the social scientist. And in the process they have come into communication with one another and with the community at large. They may have made no "longterm contribution ... to social intelligence," but they have taken a step in that direction.

Librarians, along with representatives of other local agencies, have taken part in most of these surveys. I am afraid, however, that rarely have they assumed leadership. And this brings me back to Dr. Lasswell's proposal. How can he expect librarians to take the initiative in setting up a highly complicated and indefinitely prolonged research project in the social history of communication, when they have on the whole not been able, for one reason or another, to take leadership in research projects at a much more elementary level and in which there is already widespread interest? Has he misjudged the librarians after all?

\section{The Function of the Library}

I do not think that it is so much a question of misjudging librarians as of misjudging the central function of the institution to which they are attached. It is true that one of the 
functions of the public library is to "prepare the sources for future historical and scientific understanding of the ever-expanding present" -especially those sources which relate to the particular community and region in which the library is located. But I think Dr. Lasswell is going a little too far when he goes on to conclude from this that "the anticipation of useful sources is the peculiar challenge of librarianship."

This kind of statement, it seems to me, assumes that the primary function of the institution in question is that of acting as a "storehouse of culture," and that the primary function of the librarian in such an institution would be that of preparing, collecting, selecting sources for future scientific and historical researchers. Now there should be, and there undoubtedly are, many libraries and librarians in this country to whom this description applies. But to suggest that this should be the major function-or even a major functionof the public library is, it seems to me, to betray a misunderstanding of the role it plays in modern American life.

It is difficult, as any librarian will confess, to talk in terms of the function of the public library, but William S. Learned came as close as anyone to describing it in a single phrase when over twenty years ago he called it the "diffusion of knowledge." "A modern public library," said Learned, "can completely justify its existence only by means of a diversified service that makes useful ideas contained in print helpful and easily available to all of the elements in the supporting population." To put it another way, you might say that the public library exists primarily to assist in the communication of useful ideas. (And most librarians would not limit themselves to "useful ideas contained in print" but would include other modern media of communication, such as films and radio.) The emphasis throughout is on service, not storage. Books and other materials are for the most part essentially expendable items to be selected primarily on the basis of their usefulness in communicating ideas.

With a clear mandate to promote the diffusion of knowledge, librarians have a much more dynamic role to play than simply that of "deciding what to conserve and what to neglect." They have to devise ways and means of taking these "useful ideas" to the people. They have to be active agents in the process of communication, and so far they have only just begun to perform this task. It is the performance of this task-the task of helping to keep the people in touch with the knowledge uncovered by modern sciencethat is the peculiar challenge of librarianship.

The need for greater participation in the scientific study of communication is, as Dr. Lasswell points out, very important. Theoretically there is no reason why librarians should not engage in it, should not at one and the same time be agents in the dissemination of ideas and collectors of sources for future historical and scientific understanding. But since the average library budget and building are painfully limited, the average librarian will probably find himself unable to perform both functions.

I suspect that the answer to Dr. Lasswell's proposal lies in making the collection and selection of source material for future research in the science of communication a cooperative project. It might be conducted by individual libraries strategically located in the various regions of the country but supported by special grants from public funds and from interested associations and foundations. In this way it would not be in competition with the public library's primary function of promoting the wide dissemination of the knowledge that is continually being placed at our disposal. For we live in an age of transition, and unless today's useful ideas are effectively communicated to the people, our carefully collected sources for future investigation may tomorrow be reduced to rubble. 


\section{New Tools of Communication}

Approaching the subject of the science of communication from the viewpoint of the political scientist, Dr. Lasswell has, in his interpretation of the function of librarianship in the field of communication, placed emphasis upon the research function of the library:

... one of the major functions of the library in civilized society is to prepare the sources for future historical and scientific understanding of the ever-expanding present.

.. . the anticipation of useful sources is the peculiar challenge of librarianship.

... it may be feasible for librarians themselves to take the leadership in the gathering of data. Emphasis has been put upon the scientific importance of describing the changing structure of community attention.

Addressed as it is to the readers of College and Research Libraries, Dr. Lasswell's approach to the subject has much to commend it, particularly for those readers who are librarians in university or other libraries in which the research function is dominant. Certainly librarians need to preserve and provide records and data for use by scholars, both contemporary and future. Certainly as librarians we need to be active participants rather than passive observers; and the science of communication, as Dr. Lasswell points out, offers genuine opportunity for active and significant study in the science of communication in terms of its community (broadly interpreted) implications.

In the space at his disposal Dr. Lasswell could not give a comprehensive discussion of the implications of the service of communication for libraries. One obvious, and to this writer important, relationship which he neglects is the responsibility of librarians to know and to utilize varied means of communication in their own work. Traditionally libraries have collected, preserved, and circulated the printed page. The new science of communication has conclusively shown that the printed page is but one means of preserving and of transmitting knowledge-is but one agency of communication. The radio, the motion picture, recordings, posters, slides, radio transcriptions are other usable aids to communication that have obvious value.

Implications for colleges of the educational programs of the armed forces have not yet been defined. It is clear, however, that in these programs aids to teaching other than books and lectures have played important roles. The experience and findings of the armed forces, plus the inevitable improvement in the quality of audio-visual aids due to technological advancements, indicate a trend toward significantly increased use of nonprinted aids to learning in the colleges of tomorrow.

The writer has reported elsewhere ${ }^{1}$ that although more than 90 per cent of some four hundred colleges studied provided visual education science, less than ro per cent of the colleges centralize this service in their libraries. Significantly, however, half of the colleges indicate that in their judgment the library should be the centralizing agency for visual education service.

This situation offers a challenge, an opportunity, and a responsibility to the college librarian. We, as librarians, can choose to be passive observers of an inevitable trend which will change teaching, advance learning, and, whether we like it or not, modify the function of the library. On the other hand, as college librarians we can be active leaders in providing through our libraries the very best aids to communication and to learningmotion pictures, recordings, radio transcriptions, slides, and other aids as they are developed and prove useful.

My initial thought in reading Dr. Lasswell's article was one of regret that he had failed to stress the important fact that the library which recognizes the implications of the science of communication will broaden its concept of library materials to include the latest aids to communication and to learning. On second thought, however, I am almost pleased that Dr. Lasswell neglected this important implication for the college library, for his neglect has given me an opportunity once more to state my conviction that as college librarians we must take leadership in providing and encouraging the use of the newer tools of communication.

1 Johnson, B. Lamar. "Audio-Visual Aids and the College Library." College and Research Libraries $5: 341-46$. September 1944. 


\section{Safeguarding the Sources:}

New Aspects of an Old Function

Reduced to simplest terms, the essential functions of a library can be stated as two: preservation and distribution. During the past century, in the popular mind at least, the second has assumed the greater importance. Nor has this been discouraged by the librarians themselves, as with the growth of the public library movement they sought to progress from the role of purveyors of polite literature to that of educational agents. Time was (and not so long ago) that scorn was freely directed against the preservative instinct supposedly inherent in the old-school librarian. Yet, since the effectiveness of the distributive function depends on the care and discrimination with which material has been collected and preserved, it can hardly be denied that collection and preservation still constitute one of the library's prime functions. Implicit in the term "preservation," however, is the duty of knowing what to preserve and how to make it available.

There is nothing new, of course, in the thesis that librarians should act as custodians of the sources of research. This is what they have been for centuries, following as best they could the changes and developments of research methods-sometimes overwhelmed by the mass of material; sometimes discriminating in selection, sometimes not; of ten skeptical both of the type of material used by investigators and of the value of the conclusions drawn by them. What Dr. Lasswell has done is to enlarge our conception of the means by which social history can be observed and recorded. Many of us have long realized the value to research of newspapers, letters, diaries, posters, photographs, business ledgers, minutes of societies, files of correspondence, scrapbooks, and numberless other things. In my own case, I found at Oberlin both a well-established tradition of this kind and a community already accepting the library as a natural repository and source of information on local matters. The general problem, however, is to continue to emphasize anew or, in some cases, to begin the exercise of the library's function as a repository. There must certainly be added an appreciation of the newer media for influencing social attitudes and thought.

When we begin to consider how to adapt our methods to these newer media, as suggested in the article under consideration, two difficulties at once present themselves. First, there is that of determining the field in which we shall work, the material in which we shall specialize, and how to relate our efforts to research in the wider areas. It is my own feeling that research in these areas-regional, national, and international-has never been able to make sufficient use of the more intensely local sources. Whether this has affected in any way the validity of such research is hard to say, but it might well be that the availability of a greater mass of local material would broaden and strengthen its foundations.

Now the accumulation of complete records of the changing experience of a whole community would be an appalling task, and probably a more or less fruitless one. Working on a more sensible basis of careful selection, neighbor communities might better choose to follow the reactions of certain of their own characteristic racial, social, or religious groups. Thus, a heavily industrialized large town with varied foreign language groups would provide data quite different from that available in a small industrial village with a homogeneous native or fully American population. A nearby rural shopping center would yield another type, a purely residential town still another. Any such scheme, it goes without saying, will be effective only after careful study and a well-planned allocation of function. For many purposes social agencies and institutions of elementary and higher education offer perhaps the easiest avenues of approach, because they have often been called on before to furnish material for studies and surveys. In finding and developing other sources of supply, excellent help can be obtained by arousing the interest of competent 
citizens who will cooperate in a long-range program, particularly one involving personal contacts. Granting that the American public has become pretty thoroughly accustomed to being interviewed and polled, this part of the program will have to be handled with skill and tact.

Dr. Lasswell's suggestions for gathering the different types of material bring to mind the second difficulty. It is the very real one, on the one hand, of making the public realize the value of what it can contribute, and, on the other hand, of overcoming the reluctance to surrender materials to any agency. This is particularly true of current material. Something old may be respected; anything less than fifty years old is disregarded completely. Let us not overlook, either, the fact that right now the paper salvage drive is one of the most potent agents for destroying some of the very material which should serve as sources for our future historians.

There has always been a time lag of about one generation in the stores of documents accumulated by any library. It is likewise evident that, with few exceptions, these come from families which have taken some part in public affairs and that all too often the papers are limited in their relevance to those public activities; also, that some of the most revealing-and therefore the best-are withheld or destroyed because of personal association.

The lack of care given to organization records is often amazing. To be sure, many groups are short-lived, but their activities nonetheless are of value to the future investigator. Strange as it may seem, even files of official records are often wofully incomplete.

In dealing with organization records a fairly simple procedure might be set up. Emphasis could be put on the acquisition of those of defunct or suspended organizations. Active groups could be carefully listed by name, with annotations as to changes of officers or quarters. A cross index showing objectives and accomplishments would make it fairly easy to direct investigators to the proper sources of information. Such a file could be kept up to date both by means of local newspaper items and by contact with the people concerned.

It seems entirely practical that librarians assume the leadership in a systematic but discriminating collection and preservation of data pertinent to the changing social consciousness of their communities. A study of Dr. Lasswell's paper should bring a fresh realization of an expanding responsibility.

Comment by Brother Aurelian Thomas

\section{Cooperation in Communication}

The first reaction of the wartime librarian to the complexities inherent in the suggestion of enlarging the scope of the librarian's work will be one of irritation at the prospect of competing at this busy time with other members of the profession in order to be abreast of modern movements. The second reaction, primarily that of such librarians as those in colleges of engineering, is that there can be no relation between Dr. Lasswell's suggestions and the work of the engineering librarian. A third reaction may be that there has been a straining after effect in an effort to produce a science from a collection of data, a science not justified by the presentation of a few isolated premises.

To enlarge my first reaction, may I say that we should present this prospect in the light of the halcyon days ahead when war schedules shall have been outmoded, when budgets are once again normal, and when a whole new batch of library assistants is ready and eager to enter the field of service in the library. It is not necessary to deny the need of an expanded program to meet the needs presented in this paper. If the efficiency of the library can be increased, if the field of service can be adequately expanded, the compensations offered by the study of communication can be justified. But is this a propitious time to start such a project?

It is true that the technological librarian, as such, can find small room in his program for interest in materials communicated. $\mathrm{He}$ has his own type of growing program. In this very field the means of communication have 
already given him a vast literature, as shown by the importance placed on communications engineering. $\mathrm{He}$ is engaged in the study of the myriad electrical phenomena that permit the spoken word to be recorded for sound tracks, to be broadcast and televised, or to be simply telephoned through wireless media or the more general communications circuits. $\mathrm{He}$ is himself enmeshed in an ever-widening universe. $\mathrm{He}$ is ever on the frontier of new discoveries, particularly now that the war need has stepped up the movement of invention and research as never before. $\mathrm{He}$ is familiar with Morse's mighty "What hath God wrought;" with Bell's frantic "Come here, Mr. Watson, I need you ;" and with the familiar "One, two, one, two. Testing," of the modern public address system. From these, as a student of the social sciences, he might branch into a study of the materials communicated. As a member of the modern community, he might and should be interested in the means of persuasion and information so prevalent today. But as a strict technician he is the silent witness of all the babel, with no interest or stake in any of it.

\section{A Nebulous Basis}

For the third group, those who see in communications study a science whose basis is more nebulous than real, Dr. Lasswell has produced an excellent groundwork. A further clarifying of what the field embraces will provide for these a more assuring indication of its authenticity.

Reversing these listings of the paper under discussion to focus on the genuineness of communications study as a science, the author has not only made an excellent case for his study as a distinct study but one worthy of the most general and universal consideration. We are, all of us, constantly confronted by the admonition to "say something." Only the cataclysm of war has brought to our attention the world-shaking importance of something we might say. The spoken word is a powerful means of opening the mind, of changing life habits, and of fostering philosophies that may, in time, shake the very foundations of our world. These tremendously important potentialities for the regeneration or damnation of millions we have often abandoned to forces whose use of this power might easily be the destruction of what we hold dearest in the world. Cavil as we will about the banalities of the radio and of the screen, abandon them if we wish to the unlettered for whom they seem so often to be prepared, we still have in them a weapon of whose force we have been made more and more conscious.

There is really nothing novel in this paper as concerns the things that are to be collected and stored for reference use. Librarians have already admitted microfilm, microprint, photographs, radio scripts, and recordings into their collections. The utility of these materials and the ease with which they may be classified have already been adequately demonstrated. What is now asked is a difference in approach and in the appreciation of the matter to be collected.

\section{Fate of Technocracy}

There is a certain danger of being so devoted to a passing idea that one might provide a tremendous outlay in order to be well supplied with reference to a developing science, only to find that it has been outmoded, transformed, or by-passed. Witness the upheaval some time ago on the subject of technocracy. True, its scientific contributions have long since been incorporated into the general literature of the field, and its ramifications, potentialities, and influences have been relegated to their proper place in the general study of sociological trends; but the library upheaval at such a concept found laudable and ardent concern and enthusiasm over a science whose development promised to shake the world, only to run its course swiftly earthward to comparative unimportance.

The question as to whether or not a library will take up the suggestions offered in this paper involves the viewpoint of novelty and fashions as opposed to the kind of opportunism that identifies leadership. In the former, the dissident librarian needs only to wait on the development of the science to cull what is necessary and useful for his public. In the latter, he assumes the role of pointing out the high points of progress and directs his readers and research workers toward the leadership they may attain under his impetus. How many a farseeing librarian of the past has grasped at a passing opportunity and has built up in his collection a mass of evidence and material whose worth can no longer be computed in dollars and cents! Such are the col- 
lections of letters, papers, reports, and other seemingly trivial material of the early republic, for instance, that have become, with the passing of time, the chief sources for the reconstruction of the lives and thoughts of the men who made America. The more we intelligently record the passing scene, the more is the need impressed on us of developing the historical sense that can aid in this reconstruction of our era, in which revolutionary methods and ways of living have been brought into common practice by the revolving wheel of time.

\section{Impossible of Achievement}

From the practical standpoint the entire plan, as outlined by Dr. Lasswell, seems impossible of achievement, but the fact that it is so all-embracing is no reason it should be rejected. As first outlined, it may have too broad a scope. As actually achieved, it may refine itself into something more workable. What is needed here is a broad general direction, a willingness to assume responsibility and control, and a conscientiousness on the part of each librarian involved of the need for his part in the realization of the great plan. $\mathrm{Li}$ brarians are noted for their spirit of cooperation. If adequate and definite direction can be given, if needs in each community can be pointed out, the ability, willingness, and assurance of cooperation can be counted on.

In the consideration of the community wastebasket versus the record of history, more emphasis must, of necessity, be placed on the public library than on the collegiate or university library. In the latter the needs will always be tempered by the curriculum or the direction of graduate research, as well as by the interests of the faculties. They will continue to revolve about the diverse branches that may be included in curriculum content. The public library, more responsive to the community mores and quality fluctuations, will be the more logical depository of this wealth of material on community thought. Here the librarian will be able to pick out what is of value in the field, to select what is germane to the objectives set, and to determine how the materials may be inteliigently and judiciously garnered and organized.

There is a growing need for just such records in our great urban centers. In a city center as great as New York, for example, no adequate record can be kept of the entire picture and its fluctuations. On so grand a scale the task would be impossible save for an institution especially equipped for this problem and for this work. But in each part of such a center there is the need to record the passing of one or more phases of urbanization. The division here is more important than in some smaller community. The march of progress, often well recorded in the more historical or older areas, is oftentimes neglected. The quiet backwash of a metropolis, approached today through the ramifications of state highways and city superhighways, is changing the composition of the community, its population, and its whole social life. The picture is a living one and still developing under our eyes. To put this into the general study of communications study will be a contribution to the story of the city as well as to the over-all story of the nation.

\section{Private Initiative}

Private initiative is the American means of achieving results. True, it is attended by enormous loss. Long after one member of the profession has gone through experimental work, he may find he has trodden the same ground more expertly covered by a fellow worker. And both may be ignorant of a third or a fourth, whose contribution might have made the general endeavor more complete and useful. Here is a waste of minds bent on the same scientific objective. As a group, librarians are notoriously profligate of their time and energy. We constantly find the efforts of a dozen members of the profession on parallel, often on identical, lines. But this is but another indication of the isolation in which one often works. The present admirable union catalog cards, the indexes to periodicals, and other cooperative and professional undertakings were not achieved until dozens of progressive men and women, feeling the need for these tools, had laid the groundwork for just the service they afford. So, in the field of communications study, we must publicize our aims and the possible methods and results for obtaining the cooperation necessary to the fulfilment of our hopes, and also bring scientific measurement to the efforts involved.

In brief, it is my opinion that the admirable thesis set forth by Dr. Lasswell defends successfully the contribution to be had in our 
library systems from the garnering of material on communications study. This cooperative function must await the time when the present crisis has passed and we are free to expand to meet the challenge of the work involved. The main source of cooperation should rather be the community library and universities within whose domain these studies fall.

The liberal arts colleges will cooperate as far as their curricular outlines demand. The technological librarian, already swamped with new subjects, will have little or no time or place for the new branch. Finally, the effective and efficient cooperative studies called for demand a maximum of publicity as well as an inspired and responsible direction, if they are to fit into the general great plan and attain their objectives.

Comment by Ralph R. Shaw

\section{Increasing the Usefulness of Libraries}

Dr. Lasswell's stimulating article outlines the field of research in the developing science of communication and indicates some of the types of information for which the social scientist of the future may come to the library. $\mathrm{He}$ indicates avenues of approach which are now foreign to our common concept of library services, and fields in which the librarian may act as a kind of laboratory assistant to the social scientist by collecting primary data which may be of value at some future time and which are not now being gathered.

The greatest problem to be faced in assembling raw data of the types enumerated by Dr. Lasswell is that the collection of local data on the scale envisaged cannot be restricted to the scholarly institutions which would, in the nature of things, be most inclined to undertake some or all of the projects outlined. Rather, it would require intensive work on the part of thousands of librarians of small public libraries if the result is to help us "to permeate into the lives of city people, villagers, and countrymen. ..." Since relatively few of the small public libraries of the country have developed collections which adequately cover the history of their localities even insofar as it is available in whole books or in periodical articles, it appears a little optimistic to hope that they will be able to collect, on any considerable scale, the types of primary materials required if we are to provide any portion of the aid to social scientists envisaged by Dr. Lasswell. Nevertheless, it may be possible for a few of the larger libraries to do some of the things which he suggests, thereby enriching themselves and the social scientists of the future.
More important, from the practical point of view, is Dr. Lasswell's review of the field of communication research and his references to literature which should be part of the equipment of every librarian.

Librarians have always been vitally interested in "who reads what," in "what reading does to people," in "why people read what they do read," and in similar problems. The evolving science of communication may offer the key to many library problems which are now handled by empirical formulae and by slogans. Practically all librarians, regardless of the type or size of their libraries, will agree, for example, that the primary function of each of their libraries is to provide the types (and quantities?) of materials required by their particular clientele, or, in other words, that each must be fitted to its own clientele.

Ranging back as far as Mary Wright Plummer's Seven Joys of Reading and earlier, we have groped for the reasons which stimulate reading. If the developing science of communication will enable us to determine in advance what books are needed by our communities (regardless of whether our service community be a university faculty, the mixed population of a large city, a more homogeneous rural group, or the staff of an industrial organization) it will add much to a science of librarianship.

\section{Old Approach}

This approach to library service, although many of its terms are new and unfamiliar, is as old as our profession. While it is doubtful that we have ever consciously weighed the "total significance" of a novel, our selection and recommendation of novels implicitly con- 
veys our subjective consideration of the factors which make up part of the concept of total significance. Perhaps we have not thought in terms of little Mary's "predisposition" when called upon to recommend a book for her, but we did consider her age, her sex, and her schooling in making the recommendation. To be sure, we have not thought consciously in terms of "media analysis" in our everyday work, yet the preliminaries to any extensive search of the literature on a research project have inevitably given weight to that. And if we have not consciously thought of "measurement of effects," one of our primary claims for support as representatives of a worthwhile social institution has been the socially desirable educational or other effect of the literature we purvey upon those to whom we supply it.

Thus, regardless of the types of libraries with which we may be associated, the science of communication outlined by Dr. Lasswell is an integral part of the fabric of our everyday work. Rudimentary as its applications to daily library practices have been so far, they offer great promise for the future. Every step ahead in the science of communication should be regarded with keen interest by librarians as a possible aid in what Jennie M. Flexner used to call "pondering the imponderables." The science of communication should gradually push back the curtain of the unknown, not only in the selection of print and other types of library materials, but also in readers advisory services and in other educational uses of print.

Careful study of all the titles mentioned by Dr. Lasswell, particularly those which he lists in footnotes $4,5,7$, and 8 , would be a good way to start. These studies offer the beginnings of a rich field for research and for development of the profession of librarianship by increasing scientifically the usefulness of libraries to their public.

\section{Comment by Ralph E. Ellsworth}

\section{Communications Study and University Librarians}

Since the study of communications is new, its province is still uncharted, its terminology is still uncertain, and its methods are almost entirely borrowed. It is possible to divide communication into two approaches-physical and cultural (to borrow two terms from anthropology).

Thus, physical communication in a university library concerns itself with problems of preparing and using audio-visual aids, printing, radio, motion pictures, and other similar media. Cultural communication concerns itself with an analysis of the effects or results of the media.

\section{Physical Communication}

Librarians in universities have not been campus leaders in this field. The number of libraries that have incorporated the preparation and use of audio-visual aids in their organization is very small indeed. In most universities there are strong departments of visual aids, usually associated with the extension divisions, and librarians have had little to do with the work.
This situation promises to be an' embarrassing one now, because out of the experiences of wartime teaching we have learned that nonprint media are often more effective than are print media. If our instructors wish to take advantage of what we have learned in recent years, they will want to use audiovisual aids when making their assignments. Their reserve lists will include books, films, slides, models, etc. If they have to divide their lists and send part of them to the library and part to departments of visual aids, the procedure will be cumbersome. Likewise, from the student's point of view the syllabus will require him to study books, films, etc., but the materials will be located in different parts of the campus and he will have much difficulty in getting the two together. From the point of view of instruction and research, therefore, it appears that the library should store and provide facilities for using all types of learning tools, print and nonprint.

From the point of view of preparation of materials, there are also unsolved problems. Several colleges and universities, as well as 
commercial agencies, have prepared radio and motion picture scripts and films that are first-rate instructional and research tools. The films can usually be purchased at the source and so can the scripts of the radio programs. But one cannot buy the script of a music broadcast, and the script of a speech is not the same as the speech. It is not economical for each university library to make recordings of the university's radio broadcasts.

Thus, it would seem that educational broadcasting stations should make and sell recordings of their important programs, and librarians should be able to purchase these just as they now purchase books. They should start buying educational films and providing facilities for using them along with ordinary library materials. Their viewing equipment should be primarily for the individual. They should also have viewing rooms for classes if they have the space. Otherwise, they should be prepared to lend the films to professors to use in classrooms equipped for the purpose.

Thus, preparation of nonprint media need not be done in the library. It can be done in the existing bureaus of visual aids and in the broadcasting studios. But it seems difficult to escape the conclusion that the resulting products must be stored and used in and from the library, which is the logical and natural place for study.

We librarians should have foreseen this difficulty years ago, but since we did not, we should hasten to correct the situation now before the war is over. Postwar students who have experienced Army teaching methods will not be patient with the situation as it now stands. This situation is presented merely as one illustration of a problem in physical communication on a university campus. A careful study of the activities of progressive schools of journalism will suggest many other similar problems.

\section{Cultural Communication}

This branch of communication concerns itself with studying the effects on the individual and on society of the use of means of communication. In its simplest aspect, it asks what is the most, effective medium for teaching a specific fact, idea, or project. In its most complex aspect, it tries to find out how existing means of communication determine what people know and think and it may also try to evaluate the effect of a specific medium on specific groups or individuals. It may even examine a given community to try to find how the beliefs, attitudes, and knowledge of its members are formed by the various communication media used in the community.

There is a growing number of students of social communication in universities. University librarians who wish to do so might well make this field the center of their research and might teach courses in some branch of the discipline. If they do so, they will find their campus a very satisfactory communications laboratory. A few specific projects around which they might organize research programs are as follows:

I. Select specific courses and study the effectiveness of various communications media for accomplishing the objectives of the course

2. Make careful studies of the learning habits and practices of individuals throughout their undergraduate years. Find out to what extent individuals acquire their basic and specific attitudes as a result of class instruction or of other noncurricular influences

3. Try to trace the influence of the propaganda materials that come into all libraries from organized interests

4. Study the availability of the various means of communication in terms of individuals and groups. How does residence in dormitories and fraternities affect availability?

5. Study the influence of student groups (religious, political, social, and scholastic) on the use members of the group make of learning tools.

These five problems serve to illustrate the approach university librarians can take if they wish to apply the study of communications to the activities of the library.

The study of communications offers to the university librarian, who is trying to find a field of activity that is related to his daily work and that is intellectually satisfying, a province that is both challenging and fruitful. It is, of course, not the only province worthwhile of study, but it is a good one for the librarian who does not wish to confine his thinking exclusively to the mechanics of his craft.

If the university librarian wishes to study communication on the campus, he will find a natural bond of interest with the professor of 
communications who is using society as his laboratory. The librarian who does some useful research in this field might well contribute to the intellectual life of his campus.

Lasswell's statement makes it very clear that university librarians do not now have the kind of source material a student of communications works with. Even more discouraging is the fact that unless the librarian understands the library needs of the social historian, he will not be able to organize a collecting program that will insure the presence of the relevant materials for future researchers.

The librarian who is associated with a university that does not have scholars actively engaged in the study of communications will have a difficult time stirring up interest in collecting for communications research. One who is associated with active scholars in the field will be more fortunate.

Area study, as the concept is now evolving, may be the curricular outlet for communications study in universities that are not now interested in cultivating the subject directly. Although area study thus far has concerned itself with large geographic units, it can just as well adjust its focus from that of the telescope to that of the microscope. In time it will inevitably do so. Insofar as it does, the librarian will find understanding colleagues to help organize a collecting program and a research program that will bring the relevant documents into the library.

The librarian who tries alone to organize a collecting program on the basis of Lasswell's concept of communication will feel like the man (as Waples once said) who tries to walk through a crowd all headed in the opposite direction. If his objective is the right one, he should be willing to go even though the going is hard. Lasswell has, indeed, paid librarians a great compliment when he holds out to them the possibility of developing a positive program which may not be appreciated today but which will be taken for granted tomorrow.

Lasswell is admittedly talking about only one part of a library book collecting program, but in this particular sphere he has offered a concept that seems clear cut and understandable and he has even told us how to go about organizing it. The next move would seem to be up to us.

\section{Comment by Elizabeth Bond}

\section{New Materials for Library Collections}

New mediums of communication have brought us new forms of material. Our collections will of necessity include not only books and pamphlets but records and transcriptions and films. History is no longer a dead thing to be studied from books alone. Armies go into battle equipped, not only with the latest inventions in ordnance and air support, but with motion picture cameras and recording apparatus. We can hear on-thespot accounts of the liberation of Paris, of the turning over of the Philippines from General MacArthur to President Osmeña, of the siege of Iwo Jima. These are preserved in transcribed form. Doubtless, also, we shall be able to hear accounts of the entrance of our armies into Berlin and Tokyo. Should not libraries collect these transcriptions?

Many libraries now have record collections, particularly in the field of music. Should not these records be expanded to include records for the teaching of languages, recordings of great literature such as the Maurice Evans Shakespeare records, and recordings of historical events? And should not the music record collections include a few Frank Sinatras and such popular items as "Mairzy Doats" and "Accentuate the Positive"? If the things to which people are exposed are important, as Dr. Lasswell says, then these items, often passed over, should receive attention. Why be jubilant over the acquisition of a collection of popular sheet music of the nineteenth century and forget to preserve the popular songs of the present?

Libraries must increase their holdings of films, not only microfilms, but motion picture films. Films, like transcriptions and records, are joining the ranks of historical source materials. History would be more vivid if we could see and hear Cornwallis surrendering 
at Yorktown or Washington bidding farewell to his troops at Fraunces' Tavern. History will be more vivid because we will be able to see and hear the events of today.

Library buildings and equipment will most certainly be affected by trends in communication. As these trends bring in new materials, they will have to be housed. Not too long ago the vertical file and the pamphlet and the map case were adequate adjuncts to the bookshelf. Now we must think about the film case, or cabinet, and the record and transcription file. The librarian will have to buy, and be familiar with the workings of, various types of reading machines and projectors. If records and films are to be circulated, containers must be developed for them for their protection in transport and for the convenience of the patron in handling them.

\section{New Techniques}

The acquisition of these new types of materials will demand new developments in the field of library techniques. The cataloging and indexing of these films and records must be developed and revised. A collection of films and transcriptions concerning World War II, for example, will need to be as carefully analyzed and cataloged as is a collection of books covering the same period. The reference librarian of the future will need to know to what audio-visual materials she has access covering a certain subject or a certain period. Does the library have the Maurice Evans records of Richard II or the Paul Robeson records of Othello? Is a transcription of General Eisenhower's charge to his troops on D-Day available? What language records can be lent in Russian? In Portuguese? The use of these new types of material will acquire significance in time.

One of Dr. Lasswell's points is that the library must decide upon the area of its coverage-must decide which areas, whether global, continental, regional, or local, will be covered "very intensively," "less intensively," or merely "extensively." Each library must determine these matters for itself. Without doubt the area of coverage and its intensity will be greatly expanded for all libraries. "Very intensive" coverage should be made by each library in its own local area, however.

Each librarian, no matter how small his community, should be responsible for the acquisition and preservation of the records of that community. And it must be remembered that even the most ephemeral of present-day material will acquire significance as time goes on.

It goes without saying that local newspapers should be preserved and they should be indexed minutely for local news. Indexing is expensive, it requires time and special skill, but it must be carried on if local records are to be conveniently accessible in the future.

Photographs, and their negatives, of local subjects should be kept, also. These, too, must be adequately classified and indexed.

Other important forms of local materials are diaries and letters. These manuscript materials will present their own special problems of cataloging and handling, but they will be well worth the effort. The Leningrad Public Library, for example, has acquired a large number of diaries kept by all sorts and conditions of people during the siege. What a store of important, firsthand information is here for the social historian of the future!

Theatre and music programs should be acquired. It is surprising how useful even a small collection can be. Local orchestra programs are important to keep. If your town has a summer festival, a winter carnival, a series of lectures, preserve the records of these events. They will be important for you to have someday.

Transcriptions of local radio programs of significance should be kept as well as radio scripts. Minnesota libraries, for example, will find important the transcriptions or scripts of the popular dramatizations of the report of the Minnesota Resources Commission, which have been coming over the air for some weeks past.

Reports of all kinds of organizations and groups and of individual events, insignificant though they may seem at the moment, should be saved. It should be remembered, too, that library records in themselves are records of social meaning.

As Dr. Lasswell says, "Research is conditioned and limited by the sources; the anticipation of useful sources is the peculiar challenge of librarianship." Libraries will have to set limitations upon their collection of materials in wider fields, but they can be extremely thorough in their collection of those at the local level. 


\section{Providing the Sources for Research}

Many librarians will concur with the statement that "the progress of social intelligence depends on the energy and vision of librarians." This is one of the reasons why libraries exist. But comparatively few of these "prepare the sources for future historical and scientific understanding of the everexpanding present." The task of providing the sources for research into the social inheritance and into the processes of social growth has been assumed to require resources of personnel and equipment not commonly found in community libraries. Now Dr. Lasswell suggests that in a quite different way many libraries can and probably should participate in the gathering of resources being illuminated by the new scientific study of communication.

Two roles not entirely separable emerge from this picture-the librarian as preserver of many media of communication (those normally acquired and those more recently developed) and the librarian as one of the community's recorders of the things which come to the attention of community groups selected for observation. Both of these roles in their fuller sense are new to most librarians. They have not been tested for their practicality or validity, although the time is obviously near when this should be done. Librarians who are equipped to deal only with the printed word are not likely to meet the needs of the new world a'coming. The question is largely how far shall which libraries go, in what direction, and to what purpose.

Dr. Lasswell makes it clear that social and political scientists of the future will want to tap many vats of material in their research into the processes of social growth which hitherto have been by-passed through ignorance and unavailability. One of the first questions librarians should ask is how far are, or should, these records be preserved by their producers? Data on this will help the librarian to keep his vision fixed on his special responsibilities and his energy stretched to cover them all in an adequate way. If selection of resources must be made it should be on the basis of a clear definition of functions and a hardheaded look at what will be involved.

Have librarians the vision called for to make a wise decision? Vision in this instance infers insight and discernment which goes beyond present horizons and which is built upon education and experience. Formal education for librarians in the art of gathering and preserving source materials now being made useful for the first time by the development of new scientific tools is only beginning. Even today the professional library schools offer those in the field little aid, for they lack the laboratories in which to test their theories. Discussion in print also needs the tether of experience to make it realistic. The profession and the library schools need the benefit of experiments which can be carried on only by libraries which have the financial, physical, and personnel equipment to give the idea a fair trial. Once the limits of library participation are clear, the education of both librarians and library trustees can proceed in a lucid manner. The best that any librarian can do, in the absence of educaton, experimentation, and experience in this particular field, is to hazard a guess at what might be done in the meantime.

It is clear that social scientists should take the leadership in working out with community agents and interested individuals a nationwide plan for channeling the resources revealed by the developing science of communication. A clear statement of methods and goals should be prepared. If libraries equipped with the tools for preserving and translating the collected records appear to be the best depositories, ways should be found for giving them additional financial support. Personnel trained for this special undertaking would be scarce, but some librarians would welcome an opportunity for participation in well-formulated plans for the gathering of local sources and for the scientific study of communication. Freed from some of the pressure of other manifold duties, some of these might also take the initiative in leading community interest in the enterprise. 